\title{
MONITORAMENTO DA DATA DE PLANTIO DA CULTURA DE VERÃO POR NDVI/MODIS NA REGIÃO DE OURINHOS-SP
}

\author{
Tatiane da Silva Gregório ${ }^{(a)}$, Leonardo Auge Levyman ${ }^{(b)}$, Edson Luís Piroli ${ }^{(c)}$, Daniela \\ Fernanda Silva Fuzzo ${ }^{(d)}$, \\ (a) Graduando em Geografia, Universidade Estadual Paulista - UNESP - Campus de Ourinhos - E-mail: \\ taty_gregorio@hotmail.com \\ (b) Graduando em Geografia, Universidade Estadual Paulista - UNESP - Campus de Ourinhos - E-mail: \\ leoauge@ hotmail.com; taty_gregorio@ hotmail.com. \\ (c) Profa. Dra. Subs, Universidade Estadual Paulista - UNESP - Campus de Ourinhos. Email: \\ daniela@ourinhos.unesp.br \\ (d) Professor Assistente Doutor do curso de graduação em Geografia da Unesp - Campus Experimental de \\ Ourinhos e do Programa de Pós-Graduação em Geografia da Faculdade de Ciências e Tecnologia da Unesp - \\ Campus de Presidente Prudente. E-mail: elp@ourinhos.unesp.br
}

\section{Eixo: GEOTECNOLOGIAS E MODELAGEM ESPACIAL EM GEOGRAFIA FÍSICA}

\begin{abstract}
Resumo.
A utilização do sensoriamento remoto para monitoramento agrícola viabiliza o monitoramento de culturas, desde o plantio até a colheita. O NDVI é uma ferramenta que permite não só mapear a vegetação, mas também medir sua quantidade e condição em uma área. O objetivo foi monitorar a data de plantio das culturas de verão na região de governo de Ourinhos-SP, por meio de imagens NDVI-MODIS, o período analisado foram os anos agrícolas de 2012/13 à 2015/16. A partir disso, foram selecionadas as composições multi-temporais em RGB das imagens de NDVI, de modo a destacar apenas a cultura verão. Assim, afirmamos que por meio de imagens orbitais é possível observar o início da data de plantio na região, uma vez comparadas com dados CONAB. A importância em fazer essa análise, se deve principalmente por ser uma das poucas áreas do Estado de São Paulo onde se encontra a produção de soja.
\end{abstract}

Palavras chaves: geotecnologias, sensoriamento remoto, semeadura, índice de vegetação.

\section{Introdução}

A agricultura tem uma grande influência no regimento econômico do país, influenciando o desenvolvimento de um determinado espaço. De acordo com a Food and Agriculture Organization of the United Nations - FAO (2009) o Brasil é um dos maiores produtores mundiais de soja e milho. Segundo o levantamento feito pela Companhia Nacional de Abastecimento - CONAB (2016), a previsão de área plantada na safra 2015/2016 para a cultura da soja é de 33.189 milhões de hectares, e para a cultura do milho estima-se 15.279 mil hectares. Segundo a FAESP (Federação da Agricultura do estado de São Paulo - 2012), a soja é o segundo grão mais importante no Estado de São Paulo, com uma produção de 26,4 milhões de sacos de 60 kg sendo a região de Ourinhos uma das principais áreas de produção de soja no Estado de São Paulo.

A escolha da época certa para o plantio é um dos fatores determinantes para o sucesso no crescimento e rendimento da cultura, que necessita de uma certa quantidade de água disponível no solo para o 
início de seu ciclo vegetativo (ARAUJO, 2010).

Além disso, a partir do conhecimento do ciclo fenológico da cultura se faz necessário conhecer também sua capacidade de reflectância ao sensor em orbita, para Moreira (2005) cada alvo (asfalto, vegetação, água, entre outros) tem comportamento espectral diferente na mesma condição ambiental. Segundo o autor, os dados de reflectância dos alvos podem ser transformados em índices de vegetação, os quais foram criados com o intuito de ressaltar o comportamento espectral da vegetação em relação ao solo e a outros alvos da superfície terrestre, sendo que um dos índices mais utilizados é o NDVI (Normalized Difference Vegetation Index), esse índice nos permite fazer análises por meio de imagens de satélite em uma determinada área de estudo. Sobre essa premissa, o objetivo deste trabalho foi monitorar o início da data de plantio da cultura de verão, na região de governo do município Ourinhos - SP, o período analisado foram os anos agrícolas de 2012/13 a 2015/16 por meio de imagens do produto NDVI do sensor MODIS/Terra.

\section{Material e Métodos}

A região de estudo está localizada no sudoeste paulista, compõe a região de governo de Ourinhos, composta por 12 municípios, sendo eles, Bernardino de Campos, Canitar, Chavantes, Espírito Santo do Turvo, Ipaussu, Óleo, Ourinhos, Ribeirão do Sul, Salto Grande, Santa Cruz do Rio Pardo, São Pedro do Turvo e Timburi, conforme demostrado na Figura (1), a região apresenta forte representatividade no cenário agrícola em relação à cultura da soja (SILVA et al., 2015).

Silva-Fuzzo (2015) afirma que o ano agrícola da soja na região do médio Paranapanema geralmente inicia-se setembro/outubro como o mês de plantio e abril como o mês de colheita, podendo isso ser mudado de acordo com fatores ambientais ou antrópicos.

Os dados orbitais foram obtidos pelo satélite Aqua/Terra do sensor Modis (produto Mod13q1), com resolução espacial de $250 \mathrm{~m}$ e resolução temporal de 16 dias, as imagens encontram-se gratuitamente no site da NASA (Administração Nacional do Espaço e da Aeronaútica) $<$ https://reverb.echo.nasa.gov/reverb> em formato hdf, sendo necessário converter as imagens em geotiff pelo programa MrTools, o período analisado foram referentes a primeira quinzena dos meses de setembro a abril dos anos 2012 a 2016.

A partir disso foram selecionadas as composições multi-temporais em RGB (Red,Green,Blue) das imagens de NDVI, de modo a destacar apenas a cultura verão. As imagens do período que apresentaram maior vigor vegetativa foram colocadas no canal $\mathrm{R}$, em seguida as imagens com menor vigor vegetativo nos canais $\mathrm{G}$ e B, como proposto por (ARAUJO, 2010), como mostra a Tabela 1, segundo o autor, se o ciclo da cultura inicia-se no primeiro decêndio de outubro, provavelmente seu pico vegetativo estará no primeiro decêndio de dezembro, assim, a imagem correspondente ao primeiro decêndio de dezembro será alocada no canal $\mathrm{R}$, a imagem referente ao inicio do ciclo da 


\section{OS DESAFIOS DA GEOGRAFIA FÍSICA NA FRONTEIRA DO CONHECIMENTO \\ Instituto de Geociências - Unicamp \\ Campinas - SP \\ 28 de Junho à 02 de Julho de 2017}

cultura e ao menor valor vegetativo (primeiro decêndio de outubro) foi colocada no canal G e no canal $\mathrm{B}$ a imagem com o segundo decêndio de menor vigor vegetativo (segundo decêndio de outubro). Para o processamento das imagens NDVI na caracterização em RGB foram processadas pelo programa ENVI 4.5, e recortadas pelo Arcgis 10.5.

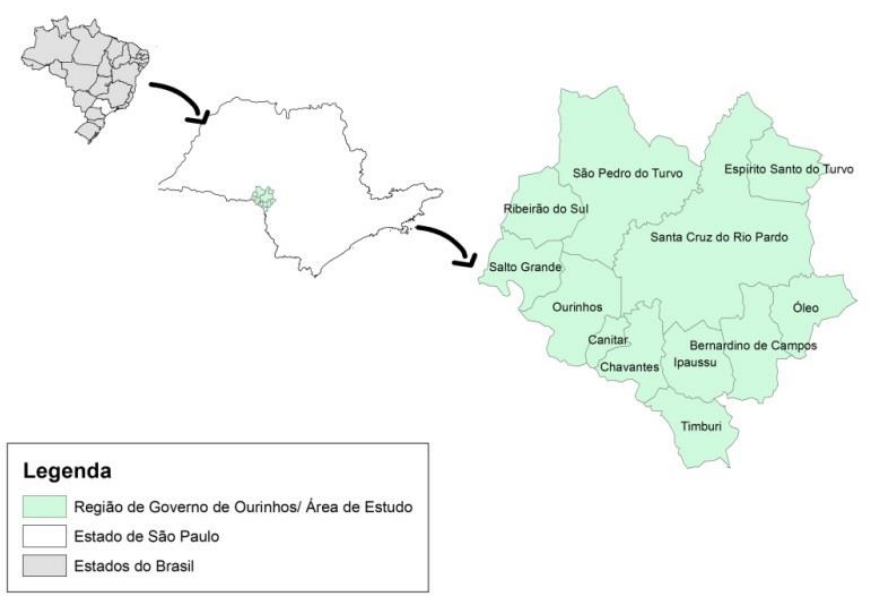

Figura 1- Localização da área de estudo

Tabela 1 - Composições multi-temporais em RGB das imagens NDVI-MODIS.

\begin{tabular}{|c|c|c|c|c|}
\hline Composições & $\mathbf{1}$ & $\mathbf{2}$ & $\mathbf{3}$ & $\mathbf{4}$ \\
\hline $\mathbf{R}$ & $\mathbf{1}^{\mathbf{a}}$ quinz. Janeiro & $\mathbf{1}^{\text {a }}$ quinz. Fevereiro & $\mathbf{1}^{\text {a }}$ quinz. Março & $\mathbf{1}^{\mathbf{a}}$ quinz. Abril \\
\hline $\mathbf{G}$ & $\mathbf{1}^{\mathbf{a}}$ quinz. Setembro & $\mathbf{1}^{\mathbf{a}}$ quinz. Outubro & $\mathbf{1}^{\mathbf{a}}$ quinz. Novembro & $\begin{array}{c}\mathbf{1}^{\mathbf{a}} \text { quinz. } \\
\text { Dezembro }\end{array}$ \\
\hline B & $\mathbf{1}^{\mathbf{a}}$ quinz. Outubro & $\mathbf{1}^{\text {a }}$ quinz. Novembro & $\mathbf{1}^{\text {a }}$ quinz. dezembro & $\mathbf{1}^{\text {a }}$ quinz. Janeiro \\
\hline
\end{tabular}

\section{Discussão e Análise dos Dados}

Foram mapeados as época de plantio da cultura de verão para a região de governo de Ourinhos- SP, através de composições quinzenais de imagens em RGB das safras em estudo, desta forma, o mapeamento da cultura mostrou apenas as regiões onde havia plantio.

Neste procedimento foram necessários selecionar áreas de interesse, no caso, o maior vigor vegetativo da cultura de verão dentro de cada composição. A melhor forma encontrada para mapear a época de semeadura da cultura de verão na região de governo de Ourinhos, foi através de composições quinzenais de imagens em RGB das safras em estudo, desta forma, o mapeamento da cultura por quinzena mostrou apenas as regiões onde havia plantio. Através da Figura 2, é possível observar a evolução do plantio em toda a região ao longo das quinzenas para cada safra.

Criou-se composições multi-temporais coloridas em RGB, compostas por três imagens decendiais cada, desde o início da data de plantio até o período que compreende o pico do ciclo vegetativo da cultura de verão, no total foram criadas quatro composições para cada safra. Podemos observar as Figuras a,b,c, e d (Fig.2) que a cultura de verão inicia-se nos meses de setembro e outubro 


\section{OS DESAFIOS DA GEOGRAFIA FÍSICA NA FRONTEIRA DO CONHECIMENTO \\ Instituto de Geociências - Unicamp \\ Campinas - SP \\ 28 de Junho à 02 de Julho de 2017}

(representados pela coloração vermelha), já os nos meses seguintes, novembro e dezembro , essa coloração a não se encontra presente, mostrando que a região não utiliza o período como época de plantio.

a)
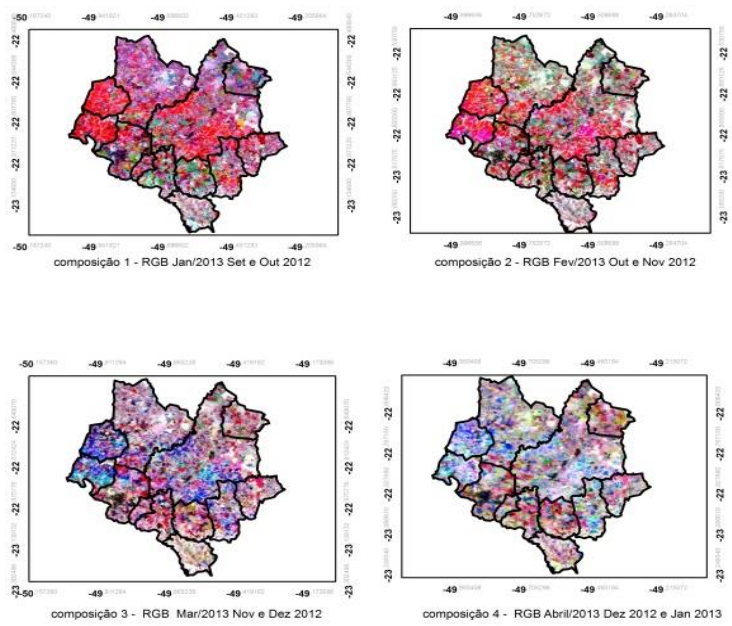

c)
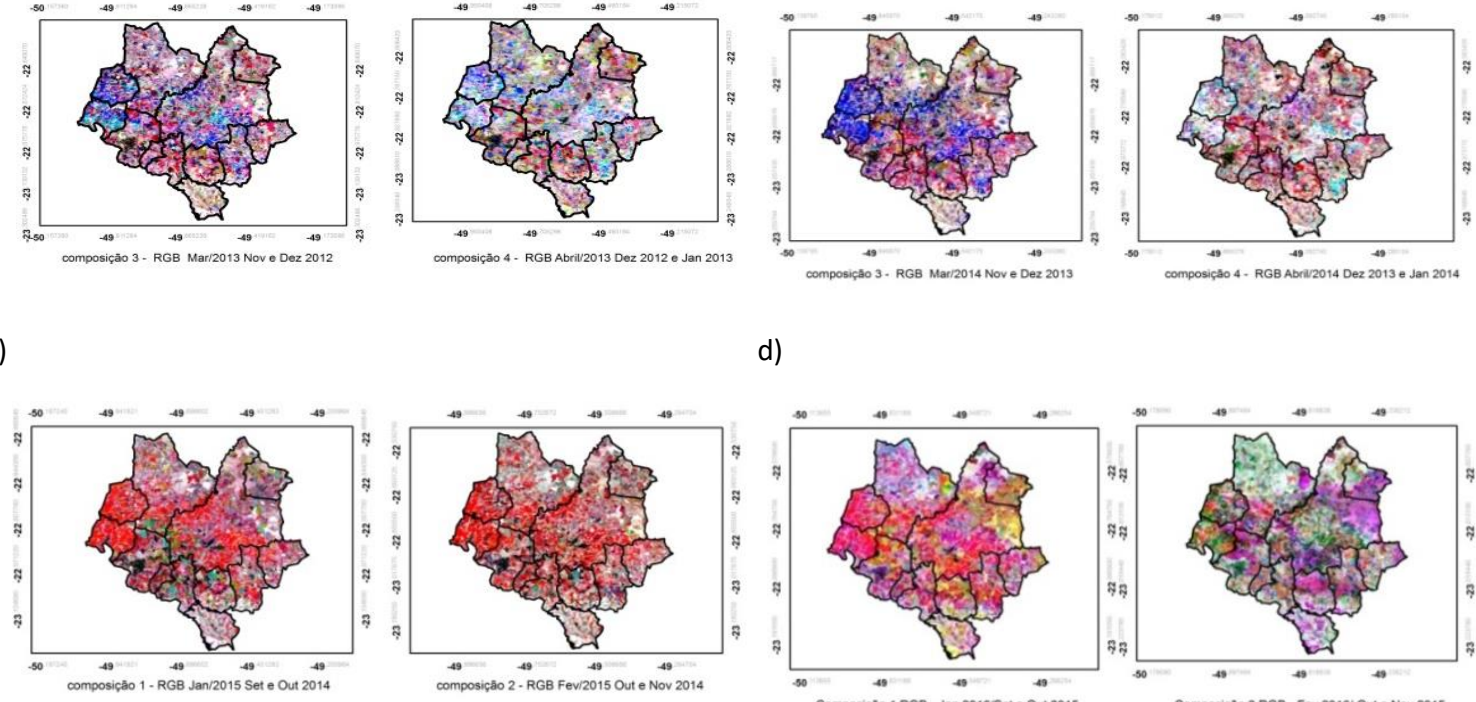

d)
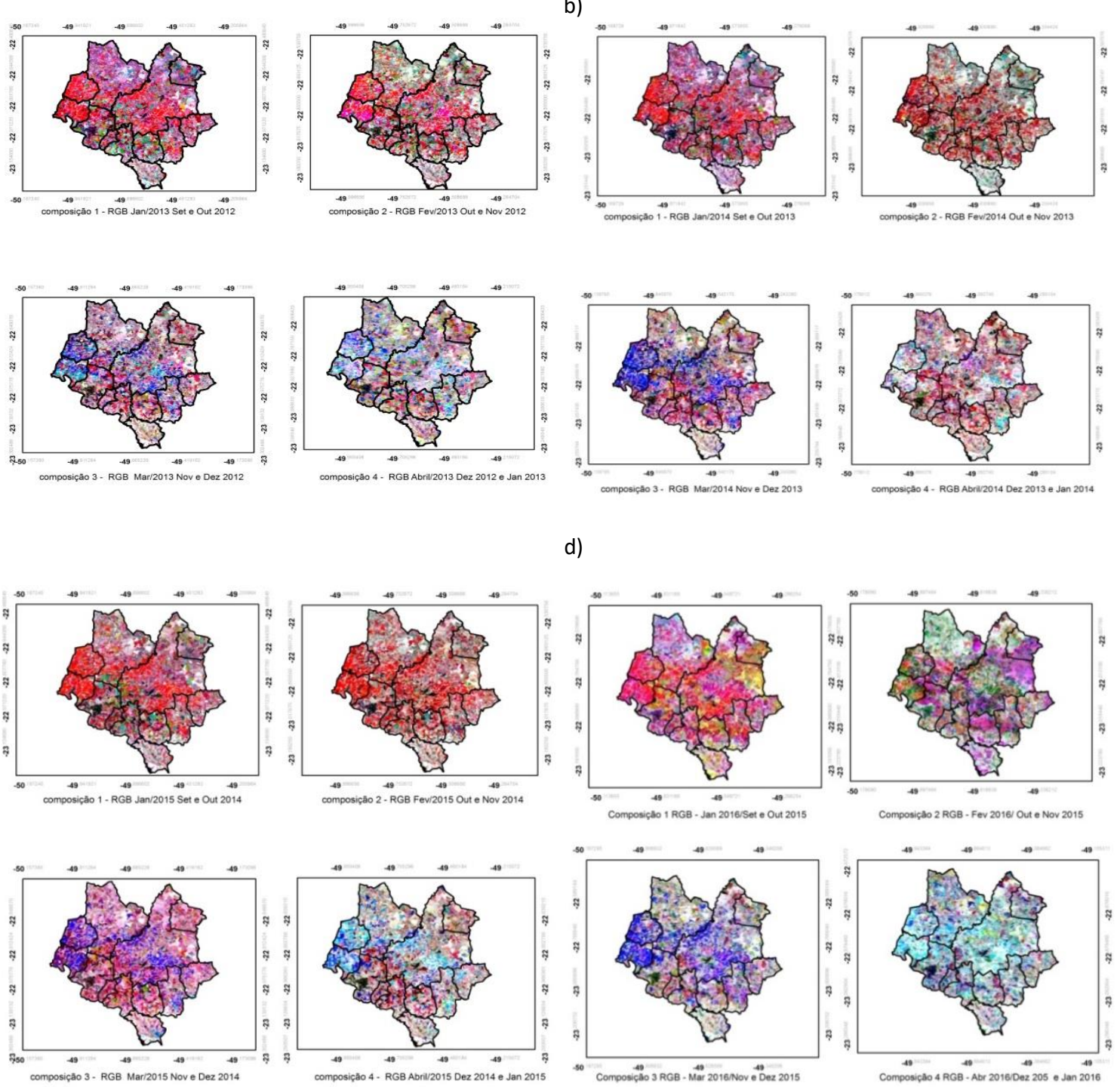

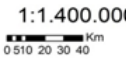

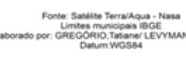

$\bigwedge^{N}$

Figura 2. Data de semeadura da cultura de verão dos anos agrícolas, a) 2012/2013, b) 2013/14, c)2014/15 e d) $2015 / 16$.

Segundo ARAUJO et al, 2013, a utilização de composições decendiais em RGB mostra-se eficaz para mapear culturas de verão, em seu estudo no estado do Paraná encontrou bons índices de acerto na interpretação do mapeamento, o autor afirma que essa metodologia permite identificar importantes áreas de ocupação de soja e milho dentro do estado. De acordo com dados da CONAB (Companhia Nacional de Abastecimento - 2016) a data de plantio apresenta maior concentração nos meses de outubro para as ultimas safras, de acordo com os mapas analisados somente o ano em comparação 
com os dados analisados somente o ano agrícola de 2015/16 apresentou menor concentração em relação ao mês anterior.

\section{Conclusões}

Os resultados mostram que as geotecnologias são importantes ferramentas para análises do espaço, e para a caracterização da vegetação de um determinado local. A utilização de composições quinzenais de NDVI mostrou-se eficaz para mapear data de plantio das culturas de verão. O método empregado permitiu identificar importantes áreas de ocupação com a cultura, além disso, permitiu observar que há diferenças de época de plantio da cultura para diferentes regiões. Desta forma, o uso do sensoriamento remoto torna-se cada vez mais importante, contribuindo ao monitoramento de áreas agrícolas, permitindo alcançar metodologias eficazes e de baixo custo. Análises futuras serão realizadas com a extração do pixel puro de soja, provindas de máscaras de produtividade, onde será possível identificar áreas da cultura bem como quantificá-la de forma precisa.

\section{Bibliografia}

ARAÚJO, G. K. D.; Higa, B.H.; Rocha, J.V.; Lamparelli, R.A.C. Máscara da cultura de verão no estado do Paraná por meio de composições RGB. Anais XVI Simpósio Brasileiro de Sensoriamento Remoto - SBSR, Foz do Iguaçu, PR, Brasil, 13 a 18 de abril de 2013.

ARAÚJO, G. K. D. Determinação e mapeamento de inicio do ciclo para culturas de verão no estado do Paraná por meio de imagens de satélite e dados de precipitação. 2010. 157p. Dissertação (Mestrado em Engenharia Agrícola) - Faculdade de Engenharia Agrícola, Universidade Estadual de Campinas, Campinas-SP. 2010.

$\begin{array}{llllll}\text { CONAB- } & \text { Companhia } & \text { Nacional } & \text { de } & \text { Abastecimento. } & 2009\end{array}$
http://www.conab.gov.br/conabweb/download/safra/4graos_07.01.10.pdf>. Acesso em: 27 de fevereiro 2016.

FAO FOOD and AGRICULTURE ORGANIZATION - Faostat. Dados estatísticos sobre a produção mundial da soja. Disponível em: http://faostat.fao.org/site/567/default.aspx\#ancor. Acesso em 21 de janeiro de 2009.

NASA - MODIS. Moderate Resolution Imaging Spectroradiometer. Disponível em <http://modis.gsfc.nasa.gov/about/> Acessado em jan. de 2017.

FAESP - Federação da Agricultura do Estado de São Paulo. Dados sobre o cultivo de soja. . Disponível em < http://www.faespsenar.com.br/faesp/home/index/> Acessado em jan. de 2017.

MOREIRA, M.A. Fundamentos do sensoriamento remoto e metodologias de aplicação. $3^{a}$ edição. 2005. Editora UFV. 320p. 
SILVA, D.F.; PRELA-PANTANO, A.; CAMARGO, M.B.P. Risco climático e produtividade da soja no Médio Paranapanema - SP: Uso de modelos agrometeorológicos para estimativa de produtividade agrícola da soja. Ed. Novas ed. Academicas. 112p. 2015.

SILVA-FUZZO,D.F.;PRELA-PANTANO,A.;CAMARGO,M.B.P. Modelagem agrometeorológica para estimativa de produtividade de soja para o vale do Médio Paranapanema-SP. Irriga, Botucatu, v. 20, n. 3, p. 490501,2015 . 